\title{
Enhancing the practice of feedback through arts: an integrated open strategy
}

\author{
Daniela Casiraghi, Bianca Santolini \\ METID - Learning Innovation, Politecnico di Milano, Italy.
}

\begin{abstract}
This paper presents the experience conducted in the framework of the Erasmus+ FeedBack project, which aims at developing the practice of feedback through arts. The article introduces the practice of feedback as essential tool to enhance teaching and learning activities in the different level of education, with a specific focus on higher education. The FeedBack project has developed an Art-Based Feedback Model, which has been firstly defined in terms of actors, who give and receive feedback through different channels. Furthermore, the model has been integrated with the concept of Art-Based Initiatives, directly related to processes of Sustainability, Inspiration and Transformation implemented in teaching and learning contexts. Through an open and integrated virtual and face-to face strategy, that includes a digital toolkit, webinars, Massive Open Online Courses, events and workshops, the Arts-based FeedBack Model has been disseminated in several countries, stimulating the discussion and innovating the teaching and learning practices. This strategy lead to positive outcomes in terms of raising awareness of the topic, supporting the design and personalisation of the feedback process itself and, thus, enhancing the teaching and learning experience, especially in higher education contexts.
\end{abstract}

Keywords: Feedback, Art Based Initiatives, Digital Toolkit, Teaching and learning innovation. 


\section{Introduction}

When designing teaching and learning processes that fosters the acquisition of theoretical concepts, methods, processes, skills, the first idea that comes to instructors' mind is the organisation of teaching and learning activities to be delivered. Within these activities, assessment plays a key role to understand the starting point from which the students learning will take place, to monitor progress and set the following steps or adjustment to be implemented, to evaluate if the results have been achieved and how the learning have been consolidated. Feedback is the element of the assessment process that strongly support its main aims, and the process of learning in general. Grant Wiggins, citing several authors (Bransford, Brown, \& Cocking, 2000; Hattie, 2008; Marzano, Pickering, \& Pollock, 2001) states that by teaching less and providing more feedback, teachers can produce greater learning. Hill (2007) identifies feedback as the element that support learners in moving round the learning cycle. It supports the process of reflection and the consideration of new or more in-depth theory, and helps the learner plan productively for the next learning experience (Multiprofessional Faculty Development, 2018). Feedback informs a student and a teacher about the performance in relation of the learning goals previously set. According to Hattie and Timperley (2007), it responds to the questions "Where I'm going", "how I'm Going" and "Where to next", supporting the redirection or refocus of the actions, both of teachers and of students. Wiggins (2012), and with him several authors, describes the characteristics of a helpful feedback which has to be goal-referenced, tangible and transparent, actionable, userfriendly (specific and personalized), timely, ongoing, and consistent. He also highlights the main problem related to the lack of time teachers and instructors lament during learning and teaching activities, but he suggests that no time devoted to feedback actually means "no time to cause learning". There are numerous strategies to provide the feedback students need. These strategies include the use of different channels, i.e. technology to provide feedback to large classrooms; the inclusion of different actors in the roles of the feedback givers, for example peers, mentors and tutors, other teachers; the implementation of different and innovative approaches, to support learning and the development both of hard and of soft skills. While the first two points are largely covered, there is limited evidence of innovative approaches used to stimulate and deliver feedback. In this context, the FeedBack project explores how Arts-based learning can be applied to the feedback practice: according to the report "The Value of Arts-Based Initiatives" by the University of Basilicata, an Arts-Based Initiative (ABI) can be defined as any organisational and management intervention using one or more art forms to enable people to undergo an art experience within an organisational context, as well as to embed the arts as a business asset (Schiuma, 2011). ABIs primary goal is to design "creative learning through an alliance with arts-based pedagogical processes" that can be applied in any subject area. This approach aims at facilitating ABIs that are "thought-provoking and capable of engaging people into reflection, self-assessment and 
development of a new and different knowledge" and can therefore be linked to the practice of feedback.

\section{The Feedback project: output and first results}

FeedBack (http://www.thefeedbackproject.eu/) is a 3 year project (September 2017 - August 2020) built upon the premises stated in the previous paragraph. The main aim of the project is the improvement of the feedback practice to enhance learning through arts. It's supported by the ERASMUS+ programme (Key Action 2, Strategic Partnerships) and involves 5 partners from 4 European Countries (United Kingdom, Italy, Portugal, Slovenia). All partners work in the field of education, from primary school to higher education.

The project is composed of two main phases: the first one is focused on research and analysis of the state of the art; the second is centred on design, production, test and dissemination of the Digital Toolkit. Aim of the Digital toolkit is to gather different ABIs to support the practice of feedback in different contexts (both in education and work environments) through different channels,both digital and face-to-face or physical. During the first project meeting (December 2017) the partnership has set a common background defining Feedback as "a gift, an energy to go on. It leads to a process of transformation that arts-based learning can enable through the facilitation of moments of reflection and, consequently, self-assessment which can support individuals to improve, change and develop". The first phase of the project, the "State of art phase", helped the partnership to tackle the definition of Art-based feedback thanks to an extensive literature review and national focus groups in the 4 Countries. The literature review covered different topics: the feedback practice and its application in workplace and education, feedback best practices, understanding and applying the feedback message, art-based approaches in education and art-based initiatives to support reflection. FeedBack Project partners planned several focus groups, involving teachers (from kindergarten to higher education), managers, coaches, higher education learners, researchers, tutors and vocational trainers. Participants were invited to share their experiences about feedback practice and to reflect on how they used it in their teaching activity. Experiences collected were highly heterogeneous, but focus groups final outputs were actually similar. All the focus group participants agreed on the effectiveness of feedback but they also expressed their uncertainty onhow to properly integrate feedback into their hands-on teaching practice. Hence, the need arose for spreading knowledge about feedback and for defining a simple model of feedback to support educators in their daily activities.

From these premises the partnership designed the "Art-based FeedBack model" (Fig. 1). Starting from a general communication process, as suggested by Ilgen, Fisher and Taylor (1979), the feedback model has been defined in terms of actors (sources and recipients) which 
give and receive feedback (the feedback message) through different channels (paper, technology, etc.). According to the model, feedback is a 3 steps process:

1. delivery: the feedback message has to be properly designed in terms of contents and time (related to specific goals) and in terms of style (tailored on the recipient characteristics) in order to support the sustainability of the process;

2. reflection: the feedback message has to spur a careful thought and inspire an attentive reflection;

3. refocus: the feedback message stimulates a change in actions, resulting in a transformation that implies learning.
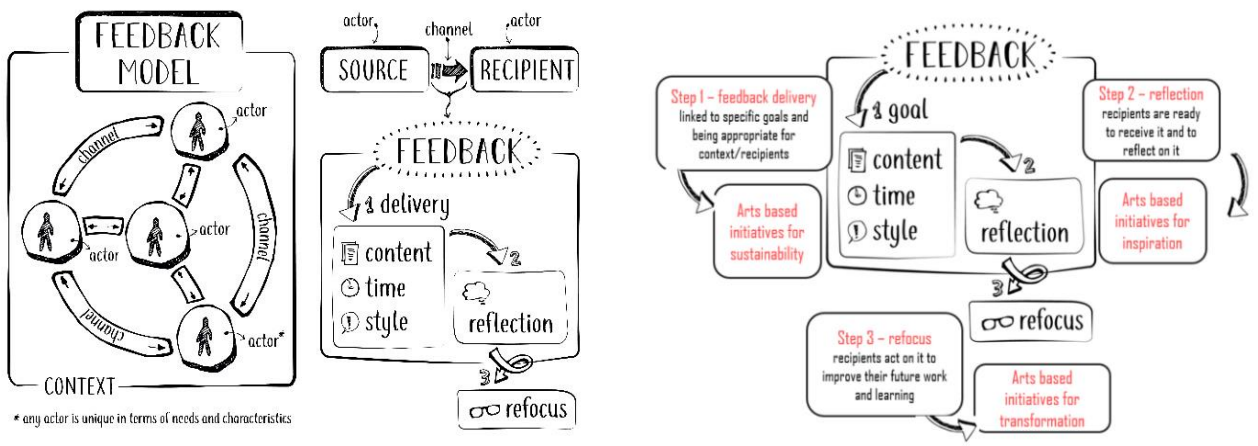

Figure 1. The Art-Based Feedback Model.

The FeedBack model has thus been integrated with the concept of ABI, defining:

- $\quad$ ABIs for sustainability: carefully planning the feedback delivery allows learners to positively accept teachers or peers advices and to take real advantage from them;

- ABIs for inspiration: reflecting on their work brings learners to a more inspired mind set to understand what they have to relearn, improve and refocus on;

- ABIs for transformation: refocusing on the initial objectives of their work helps learners to positively transform their point of view.

The State of Art report, collecting results of the first project phase, can be downloaded from the Project website (http://www.thefeedbackproject.eu/). In the second phase of the project, the partnership focused on designing and sharing the FeedBack program, aimed at supporting the application of feedback practice in different contexts. All partners collaborated in designing ABIs, that were then gathered in the online Digital Toolkit (http://www.toolkitthefeedback.eu/, Fig. 2). ABIs are categorised according to their aim (sustainability, inspiration, transformation), the time they required (5-10 minutes, 10-30 minutes, more than 30 minutes), the way in which participants are involved (single, couple, groups). 
Each ABI has a dedicated page on the Digital Toolkit in which the user finds instructions on how to implement the activity, tools needed, some additional tip and, where possible, an example of the activity performed (http://www.toolkit-thefeedback.eu/activity/unchartedterritories/).

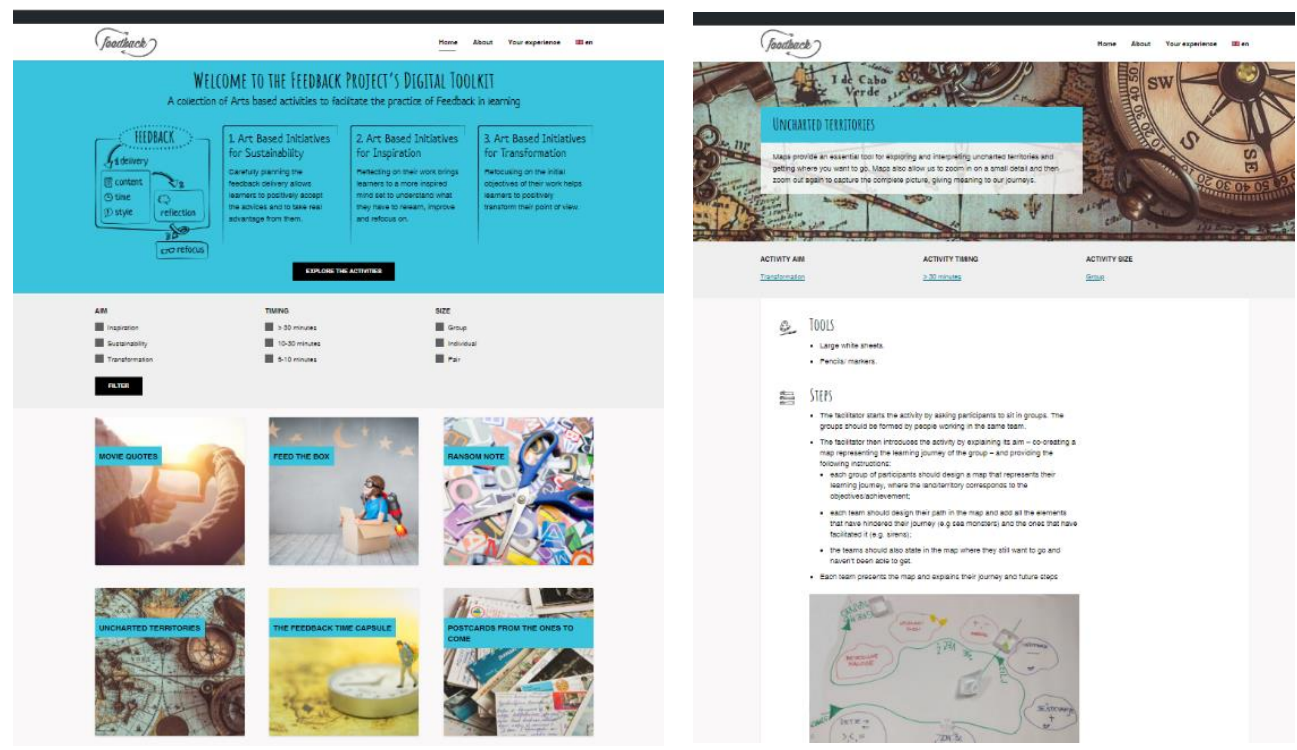

Figure 2. The Feedback Toolkit.

From December 2019 till March 2020, a Digital Toolkit pilot test was launched: it involved 100 educators from the four project Countries. The aim of the pilot test was to collect feedback about the usability of the Digital Toolkit and about the effectiveness of ABIs proposed and tools offered (Art-Based feedback design tools, Activities deck). Suggestions collected from the pilot test were crucial to successfully improve the Digital Toolkit and, consequently, to better support the practice of Art-based feedback. In particular, each ABI page has been implemented with a picture that shows the output of the ABI itself: this improvement supports the comprehension of the activity with real examples. Furthermore, starting from Art-based feedback design tools, some of the involved educators designed their personal ABI: some of them were included in the Digital Toolkit. After the testing phase, additional feedback was gathered through an online survey, directly reachable from the Digital Toolkit, and thanks to interviews with final users. Furthermore, testers from all the Countries have been invited to an online focus group to collect the last suggestions. Finally, during an online meeting, the partnership analised the collected feedbacks in order to reach a final evaluation. Data gathered though the online survey (89 responses, from the four Countries) shows positive results: $73 \%$ of users declares that the toolkit is easy to navigate. The activities in the toolkit are considered clear (77\%) and useful (79\%). Higher education 
teachers involved in the testing activities were interviewed: they declared that the art-based feedback perfectly supports the collection of information and data on skills development and teacher awareness of the real feelings of the participants. Teachers confirmed that art-based feedback activities shared in the Digital Toolkit are easily adaptable to different needs and contexts. The Art-based FeedBack practice supports the enhancement of individual skills, and creates an environment where positive attitudes are strongly stimulated. Furthermore, it facilitates interaction also when verbal or written communication is difficult, for example with international students. Finally, data collected through Google analytics from September 2019 to March 2020 (7 months) shows a massive use of the Digital Toolkit, mainly by users coming from the four project Countries. Around 800 users visited the Digital Toolkit in the analised period, with peaks of about 30 users per day. The page view number is around 7,500 with around 1,640 sessions. The average session duration is around 5 minutes, showing that users browse among the platform contents and activities.

\section{Approaches and strategies}

As stated earlier, the aim of the FeedBack project is to develop the practice of feedback through arts by designing and spreading a clear model of feedback. Goal of the project is also to set the foundations for future online and face-to-face programs about feedback practice enhancement. Core of process are design and innovation: to ensure a wider dissemination of the outputs developed and to foster the use and application of new technologies in education and training, the consortium chose to deliver the outputs through an open approach and an integrated strategy which leverage on several channels, real and digital, to reach the results.

\subsection{Open approach}

ABIs activities shared in the Digital Toolkit, all designed by the partnership and by the teachers involved in the project, have been released and licensed under a Creative Commons Attribution 4.0 International License (http://creativecommons.org/licenses/by/4.0/). Hence, all the project outcomes are, actually, Open Educational Resources: this open approach has been chosen in order to maximise the potential of future exploitation and transferability of project results. By reaching a wide audience of end-users, the partnership wants to spread and support the practice of Feedback as an integral part of the teaching and learning processes. Furthermore, the open approach strenghten the idea that Feedback project results are a source of inspiration for educators. They can adapt the ABIs proposed by the Digital Toolkit to their context and their specific needs; they can even design new ABIs. This open approach allows to integrate the Digital Toolkit into different initiatives, supporting the FeedBack project objectives. For example, the toolkit have been integrated within two Massive Open Online Courses (MOOCs), accessible from the Polimi Open Knowledge Platform (www.pok.polimi.it): "New Assessment Strategies - The magic of feedback" and 
"Progettare l'innovazione didattica". The first one is licensed under a Creative Commons Attribution - NonCommercial - ShareAlike 4.0 International License (http://creativecommons.org/licenses/by-nc-sa/4.0/) and introduces new ways to perform assessment in teaching and learning activities. The second one is a course about the integration of the design culture into teaching and learning innovation.

The FeedBack project has been presented during the Open Education Week (taking place online on 2020, March $2^{\text {nd }} 6^{\text {th }}$ https://www.openeducationweek.org/) and listed in the resource database of the event (https://bit.ly/33WiGY1).

\subsection{Integrated strategy}

An integrated digital and physical strategy have been put in place in several dimension. The "state of art" and "activities design" phases have been conducted partly during face-to-face meetings, partly during online activities and through e-collaboration processes among partners. These activities have led to the creation of two outputs, presented during the "Training for trainer" week (2019, June $17^{\text {th }}-21$ th), taking place in Liverpool with ten participants: during this event, participants designed new activities and started a discussion which has then continued online. The Multipliers events, designed and implemented to share the project results with a larger audience in the four partner countries, have been conducted both during face-to-face and online meetings. In Italy, more than 40 participants (teachers from the STEM field) subscribed to the event organized by METID - Politecnico di Milano and 26 attended on 2019, November 6th. A webinar have been organised and delivered online on 2019, November 21th, to meet the needs of those that couldn't attend: 69 participants subscribed to the event and 24 finally participated, while the others could watch the recorded meeting via zoom (http://bit.ly/381dbbt). Similar data and activities have been carried out by other partners. In Slovenia more than 35 participants, mainly teachers from primary and secondary schools, attended the multiplier event. During the event they were trained on the Art-Based FeedBack topic, planned the FeedBack process to be implemented during their teaching and learning activities, and designed new ABIs for feedback. The multiplier event was supported by an E-learning space in which all the participants could find materials and resources to support their tasks (http://bit.ly/381e8k3). The integrated digital and physical strategy has been put in place also regarding the digital toolkit: all the activities have been shared online but also collected in the "FeedBack Deck", which have been used during the multiplier events and have been shared on the online toolkit as a printable version of the activities. The deck includes two blank cards to support the idea that each person responsible of the feedback process, should use the toolkit and the activities designed as a source of inspiration, adapting them to the context and the specific needs or even defining new activities. To support the design behavior, two tools have been shared in the platform: an online form to share with the partners the new activities designed and two printable 
frameworks, which support the design both of the feedback process and of the Arts-based FeedBack activities.

\section{Conclusion}

There is limited evidence of Art based learning being applied to feedback in either the educational context or in the workplace. Within the teaching profession examples are more likely to be found in art-based subjects. The FeedBack project have designed and tested innovative feedback practices and an open and integrated strategy, to create awareness on the topic and to support design and personalisation of the process. The results show that the artbased feedback practice can enhance the teachers and learners experience. Feedback can be innovative: it has to be carefully designed by the feedback giver in order to consider differentiation and to build strong relationships between tutors and their learners. Learner are more likely to act on the feedback received to improve their learning if the feedback is structured according to their needs. A key challenge is "Change". Often educators tend to work with what they are familiar with and may be reluctant to try new ways of working, including new ways of giving feedback. However, the benefits can be rewarding for both the tutor and learner and new innovative methods applied in the classroom and in the workplace can lead to increased productivity, improved work life balance, job satisfaction, mutual respect and a feeling of "value". Innovative and creative ways of giving feedback demand further consideration: creative and innovative feedback approaches can contribute to make any learning environment, becoming more interesting, dynamic and engaging.

\section{References}

Bransford, J. D., Brown, A. L., \& Cocking, R. R. (Eds.). (2000). How people learn: Brain, mind, experience, and school. Washington, DC: National Academy Press.

Hill, F. (2007). Feedback to enhance student learning: facilitating interactive feedback on clinical skills. International Journal of Clinical Skills, 1(1), 21-24.

Hattie, J. (2008). Visible learning: A synthesis of over 800 meta-analyses relating to achievement. New York: Routledge.

Marzano, R., Pickering, D., \& Pollock, J. (2001). Classroom instruction that works: Research-based strategies for increasing student achievement. Alexandria, VA: ASCD.

Hattie, J \& Timperley, H. (2007). The power of feedback. Review of Educational Research, 77(1), 81-112.

Ilgen, D., Fisher, C., \& Taylor, M. (1979). Consequences of individual feedback on behavior in organizations. Journal of Applied Psychology, 64, 349-371.

Schiuma, G. (2011). The Value of Arts-Based Initiatives. Cambridge: Cambridge University Press.

Wiggins, G. (2012). Seven Keys to Effective Feedback. Alexandria, VA: ASCD 